\title{
Effectiveness of infrared thermography in the diagnosis of deep vein thrombosis: an evidence-based review
}

This article was published in the following Dove Press journal:

Journal of Vascular Diagnostics and Interventions

8 February 2017

Number of times this article has been viewed

\section{Maxim E Shaydakov \\ Jose A Diaz}

Department of Surgery, Section of Vascular Surgery, Conrad Jobst Vascular Research Laboratories, School of Medicine, University of Michigan, MI, USA
Correspondence: Maxim E Shaydakov Conrad Jobst Research Vascular Laboratories, School of Medicine, University of Michigan, North Campus Research Complex (NCRC), 2800 Plymouth Road, Building 26, Ann Arbor, MI 48I09, USA

Email mshaydak@umich.edu
Abstract: Venous thromboembolism is a serious medical, social, and economic problem. A number of treatment options exist to decrease mortality and morbidity in patients with deep vein thrombosis (DVT). An accurate and timely diagnosis of this condition is important to improve immediate and long-term prognosis. The standard diagnostic algorithm implying assessment of the clinical probability of the disease, D-dimer test, and venous duplex ultrasound is not optimal. Infrared thermography is a relatively new diagnostic modality under clinical investigation for various medical conditions. This study aims to review the published evidence on infrared thermography as a possible alternative tool in DVT diagnosis. The authors conclude that infrared thermography is still an experimental diagnostic tool for patients with DVT, and requires more clinical research evidence to support theoretical advantages and suggest a possible clinical application.

Keywords: deep vein thrombosis, venous thrombosis, venous thromboembolism, infrared thermography, thermography, diagnostics

\section{Introduction}

Venous thromboembolism (VTE) is a serious medical condition that comprises deep vein thrombosis (DVT) and pulmonary embolism (PE). The incidence of VTE has been estimated as $1-2$ cases per every 1000 individuals. ${ }^{1-4}$ Despite significant improvement in diagnostics, prophylaxis and treatment of this condition, the incidence of VTE, has been remaining the same over the last years. ${ }^{4}$ Acute VTE is a potentially lethal condition, with estimated 1-year case-fatality rate of $9 \%-23 \%{ }^{2,4}$ At least one-third of patients who survive will suffer postthrombotic syndrome of various severity. ${ }^{5-8}$ An individual-based treatment with anticoagulation therapy, compression therapy, catheterdirected and pharmacomechanical thrombolysis, operative thrombectomy, or inferior vena cava interruption altogether can substantially reduce VTE-related mortality, prevent VTE recurrence, and diminish postthrombotic morbidity. Thus, an accurate and timely diagnosis of DVT largely determines the immediate and long-term prognosis.

It has been noticed long ago that local changes in the body temperature may be associated with various diseases. Several literature sources quoted the following statement presumably made by Hippocrates 2 millennia ago: "Should one part of the body be hotter or colder than the rest, disease is present in that part." ${ }^{, 10}$ It is believed that an abnormal local thermal pattern is mainly caused by blood flow changes, altered metabolic activity, or both. Infrared thermography is a method to detect thermal radiation emitted from the surface of any object with a temperature higher than the absolute 
zero $\left(-273.15^{\circ} \mathrm{C}\right)$. The use of infrared thermography has been advocated to improve the diagnostics of various medical conditions, such as sport trauma, ${ }^{11}$ spinal cord lesions, ${ }^{12}$ Raynaud's disease, ${ }^{13,14}$ thoracic outlet syndrome, ${ }^{15}$ peripheral arterial disease of the lower extremities, ${ }^{16}$ erectile dysfunction, ${ }^{17}$ breast cancer, ${ }^{18-20}$ diabetic foot, ${ }^{21}$ osteoarthritis, ${ }^{22}$ complex regional pain syndrome type $\mathrm{I},{ }^{23}$ and others. Infrared thermography has also been suggested to help in follow-up after orthopedic and plastic surgery. ${ }^{24,25}$ The first purposeful use of the infrared thermography to evaluate patients with suspected venous thrombosis was reported by Soulen et al. ${ }^{26}$ This study aims to review the published evidence on infrared thermography as a possible alternative tool in DVT diagnostics.

\section{Materials and methods Eligibility criteria}

Original English language articles related to venous thrombosis and infrared thermography were eligible.

\section{Search strategy}

A search was performed in MEDLINE, EMBASE, Scopus, Web of Science, and Cochrane library electronic databases from 1900 to August 2016 using the following keywords: "deep vein thrombosis," "venous thrombosis," "venous thromboembolism," "infrared thermography," and "thermography." The literature search was limited to English language. The titles and abstracts identified by the search strategy were screened by two independent reviewers (MES and JAD).

Full text original articles that met our inclusion criteria were carefully assessed for the relevance to the aim of the study. Manuscripts that were selected pertinent to the issue by both authors were included. Disagreements were resolved by discussion. Review papers were considered, carefully read, but not included. Both duplicates in different databases and same articles published in different journals were excluded. References from the final list of manuscripts were scrutinized to include studies not obtained from the automatic search in databases. Relevant papers that were missed by systematic literature search were included (Figure 1).

\section{Results}

\section{Limitations of phlebography in the diagnostics of DVT}

As signs and symptoms of DVT are not specific, clinical assessment alone is not reliable for DVT diagnosis. ${ }^{27,28} \mathrm{An}$ ideal instrumental or laboratory test to detect DVT does not exist. Contrast ascending phlebography is considered the "gold standard" to diagnose DVT with the highest accuracy. ${ }^{29}$ It is safe to withhold anticoagulation in $99 \%$ of patients suspected for DVT who have a normal phlebogram in two projections. ${ }^{30}$ Phlebography has a number of serious disadvantages. It is an invasive and relatively expensive procedure that commonly translates into patient discomfort. It is undesirable in pregnant women because of the fetal exposure to ionizing radiation. Due to the risk of multiple adverse effects, such as allergic reactions, renal impairment, phlebitis, venous thrombosis, or even PE, conventional phlebography is rarely used as a first-line diagnostic test and is currently reserved for evaluation of patients with an unclear diagnosis or to guide interventional treatment.

\section{Limitations of venous ultrasound in the diagnostics of DVT}

Ultrasonography is a safe noninvasive alternative to contrast phlebography. Ultrasonography of the whole lower extremity is currently the standard diagnostic modality to evaluate symptomatic patients with moderate or high clinical probability of DVT according to the Wells Scoring System. ${ }^{29}$ Patients with low clinical suspicion for DVT and positive D-dimer also should be screened on ultrasound. ${ }^{29}$ Noncompressibility, which is an inability to fully collapse a vein under slight pressure with an ultrasound probe, is the main ultrasound sign highly indicative of venous thrombosis.

Despite being highly informative, ultrasound is not an ideal test for DVT. Compression ultrasound has 94\% sensitivity and $98 \%$ specificity for symptomatic proximal DVT affecting common femoral, femoral, and popliteal veins. ${ }^{31}$ However, it may be limited or noninformative in patients with morbid obesity, edema, tenderness of the lower extremity,

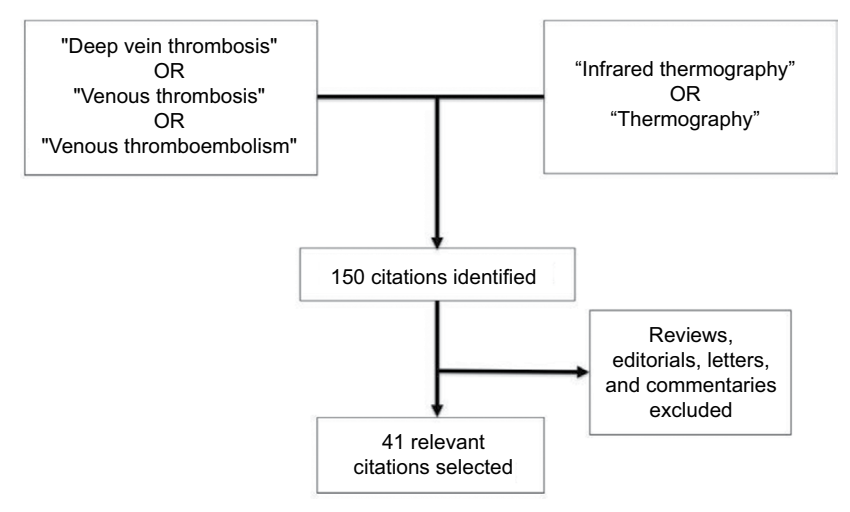

Figure I Literature search strategy. 
or the presence of immobilization devices. Evidence-based recommendations for the diagnosis of DVT also indicate that the diagnostic potential of ultrasound varies for different part of the deep venous system. ${ }^{29}$ Although monophasic flow in the common femoral vein may be suggestive of proximal disease, ${ }^{32}$ ultrasound is less useful for the detection of thrombi in the iliac veins and inferior vena cava due to inability to reliably compress them with the probe. Noncompressibility of the distal portion of the popliteal vein is associated with a positive predictive value of only $80 \% .{ }^{33}$ The positive predictive value of compression ultrasound may also be lower if venous thrombosis affects a single venous segment compared to extensive DVT. ${ }^{34,35}$ Approximately one-third of DVT cases are restricted to the calf veins. ${ }^{36}$ Undiagnosed, and thus untreated symptomatic calf DVT propagates to proximal veins in every third case, ${ }^{37,38}$ and commonly leads to PE. ${ }^{39}$ The diagnostic potential of ultrasound to detect thrombi in calf veins is limited. Despite the high specificity of $96 \%,{ }^{29}$ the sensitivity of the ultrasound to detect symptomatic calf DVT, according to the high-quality meta-analysis, is $73 \%$, at best. ${ }^{40}$

To conclude, DVT is an acute and devastating pathology that necessitates a prompt and accurate diagnostics. The current diagnostic tests have limitations. Hence, a novel highly sensitive noninvasive test would be desirable to complement the modern diagnostic arsenal for DVT. A number of alternative noninvasive tests have been suggested at different times, such as impedance plethysmography or isotope scanning with radioactive labeled fibrinogen, plasmin, or platelets. None of these techniques is deemed valid to date.

\section{Infrared thermography: the principle}

The principle of infrared thermography is based on the detection of thermal radiation emitted from the surface of human body. Any matter with a temperature of higher than the absolute zero has thermal energy consisted of the kinetic energies of randomly moving atoms and molecules. Moving particles of a different charge generate electromagnetic fields resulting in the emission of photons. Thermal radiation is the process of conversion of the thermal energy to the energy of electromagnetic waves. All objects participate in the exchange of thermal energy. Thermal energy from the objects near room temperature is mostly emitted in the infrared spectrum $(1-100 \mu \mathrm{m}) .{ }^{41}$ With an increase of the temperature of an object, the emission of infrared radiation also increases. In medical thermography heat emission from the human body usually ranges within 6-14 $\mu \mathrm{m}$. Thermography employs a special camera to remotely detect thermal radiation in the invisible infrared range of the electromagnetic spectrum from the surface of an object and convert it into grey-scale or color-scale images. Hence, a thermogram is a display of the temperature differences at the surface of the body.

The first infrared camera to detect an emitted infrared radiation at ambient temperature was created in 1959 by Astheimer and Wormser. ${ }^{42}$ The instrument utilized a radiometer and an oscillating mirror. The first thermography systems were purely qualitative, displaying thermal radiation on a photographic film as a monochromatic grey-scale image, with brighter warm areas and darker cool areas. Recent advancements in computer technology enabled full color-coded digital images with much higher resolution that translates into more precise thermography with opportunities for quantitative analysis. ${ }^{43}$

Thermoregulation is an important part of homeostasis. The average normal body temperature is regarded as $37^{\circ} \mathrm{C}$. The body temperature, however, is not constant and may be affected by many internal and external factors. ${ }^{44,45}$ Different parts of the body also have different temperatures. Thus, the normal thermogram of the resting leg appears as a relatively homogenous signal with a gradual decrease in infrared emission from the groin down to the foot. The temperature of the most distal part of the lower extremity is usually lower for $2^{\circ}-6^{\circ} \cdot{ }^{26,46}$

Temperature is symmetrically distributed, ${ }^{47,48}$ with the difference between the same areas of the right and left lower extremities $<0.2^{\circ} \mathrm{C}-0.3^{\circ} \mathrm{C} . .^{48,49}$ Due to the relatively lower blood supply, the areas adjacent to bone structures, such as patella and tibia, are cooler compared to the areas overlying calf and thigh muscles (Figure 2). A "mottled" thermogram with alternating lighter and darker areas in the thighs is also a normal pattern commonly observed in obese patients. ${ }^{50}$ An increased local temperature on a thermogram $>0.5^{\circ} \mathrm{C}$, compared to the contralateral side, may be suggestive of a pathologic process. ${ }^{51-53}$

Asymmetry of the body temperature has been associated with various pathologic scenarios. ${ }^{54-56}$ An old study that involved 121 legs suspected for DVT found that a clinical impression of an increased skin temperature by palpation only may predict DVT in up to $83 \%$ of cases. ${ }^{57} \mathrm{An}$ increased skin temperature in DVT was also noticed by other authors, ${ }^{27,58}$ and explained by an increased blood flow in superficial veins that relieves venous obstruction. ${ }^{59}$ The enthusiasm of those reports regarding the possibility of tactile diagnostics of DVT was likely overestimated. However, the infrared thermography implies the same principle, detecting slight 


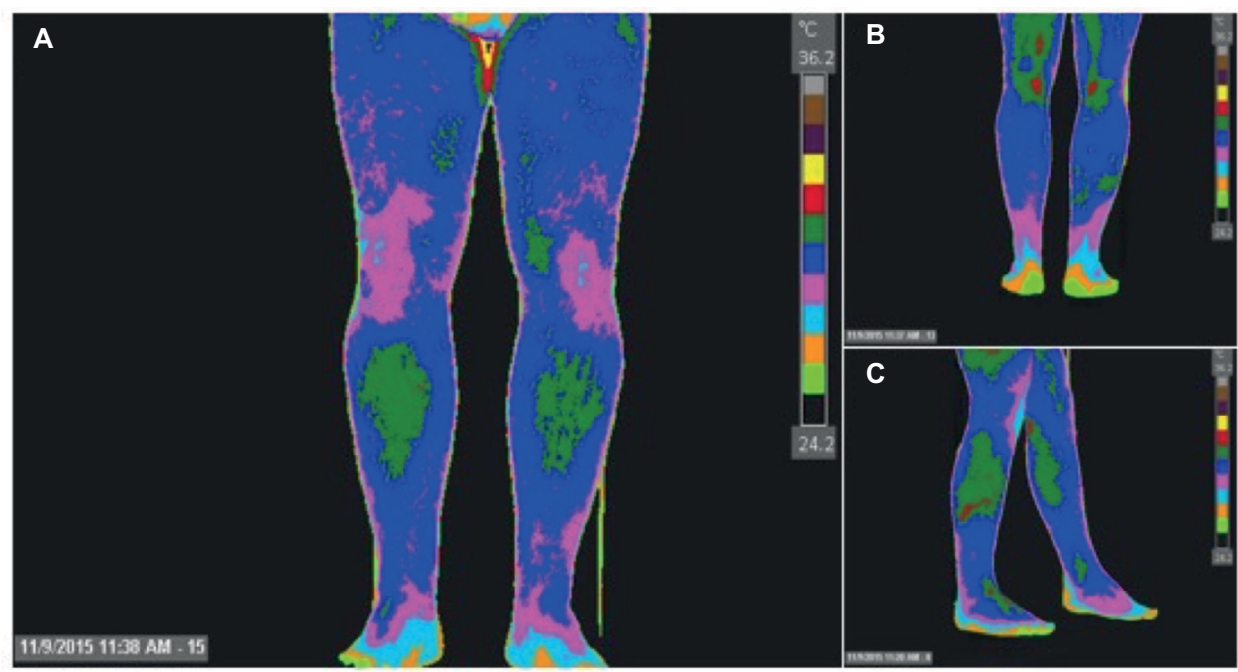

Figure 2 Thermogram of lower extremities (normal study).

Notes: (A) Anterior view. (B) Lateral view. (C) Posterior view. Images with permission of the American Academy of Thermology http://aathermology.org/. ${ }^{82}$
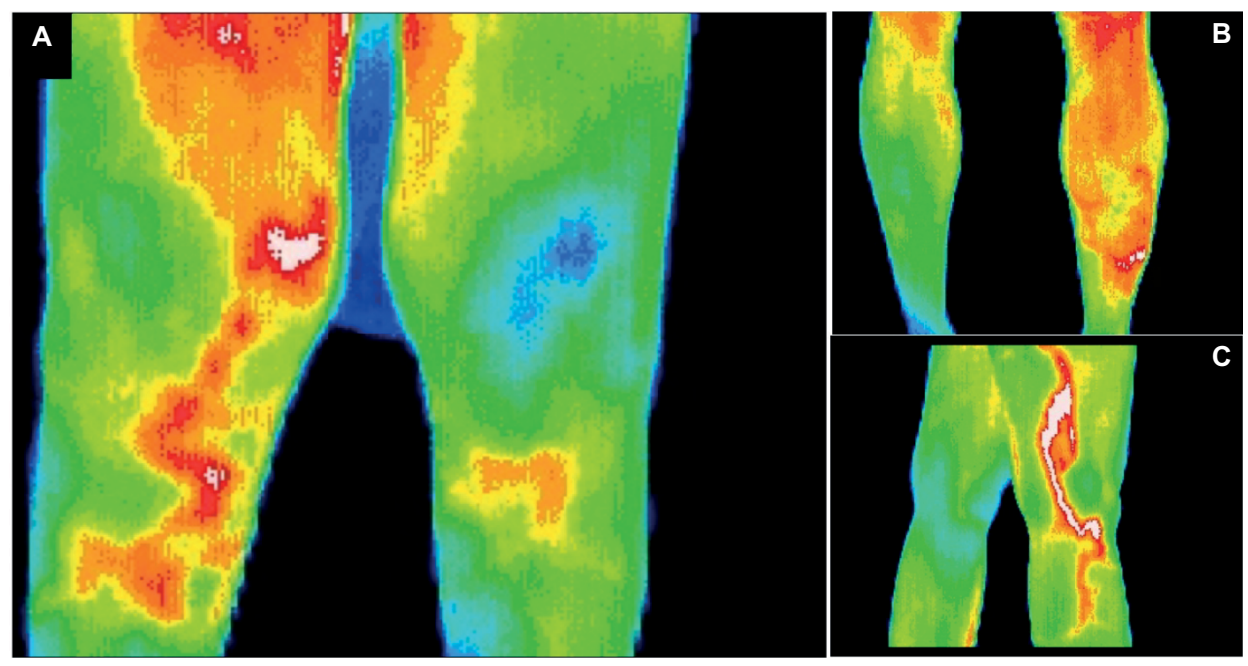

Figure 3 Thermogram of the lower extremities: deep vein thrombosis.

Notes: (A) Right femoropopliteal DVT, anterior view. (B) Right calf DVT posterior view. (C) Left femoropopliteal DVT lateral view. Images provided with permission of the American Academy of Thermology http://aathermology.org/. ${ }^{82}$

Abbreviation: DVT, deep vein thrombosis.

local changes in temperature with more sensitivity and objectivism. Several mechanisms may participate in the local increase of heat production caused by venous thrombosis. Inflammation-associated local vasodilation and enhanced metabolism lead to local hyperthermia that may be detected by thermography. ${ }^{50,60}$ In addition, an impaired venous drainage in acute thrombotic obstruction of the deep axial veins likely increases heat emission from the involved muscle groups. ${ }^{46} \mathrm{An}$ increased intravenous pressure also promotes collateral blood flow across more superficial vessels. Besides that, production of vasoactive amines may enhance local arterial circulation. ${ }^{61}$

The diagnosis of DVT by infrared thermography is mainly qualitative. Visible asymmetry with a diffused area of an enhanced heat emission over calf or thigh is suggestive of DVT (Figure 3). The loss of the normal thermographic pattern with prepatellar and pretibial areas of lower temperature is another sign of DVT. In patients with isolated calf DVT, the whole or greater part of the calf increases the temperature with the loss of pretibial coolness. ${ }^{46,50}$ More proximal femoropopliteal thrombosis is associated with an increased temperature in the lower thigh and loss of prepatellar coolness. ${ }^{46,50}$ Iliofemoral DVT appears as an increased temperature of the whole lower extremity.

\section{Methodology}

Infrared thermography registers not only the radiation emitted from the body, but may also detect transmitted and reflected 
radiation from a distant source. To avoid any errors, the study should be performed in a separate laboratory with constant temperature $\left(20^{\circ} \mathrm{C}-25^{\circ} \mathrm{C}\right)$ and humidity. Air convection should be minimized during the exam. A patient is examined in recumbent position. Both legs are elevated for $10^{\circ}-15^{\circ}$ to avoid pooling of blood in the venous system. A distance of $10-15 \mathrm{~cm}$ between the legs prevents any heat exchange. Initially, a patient is allowed to remain in recumbency for 10-15 minutes before the actual thermographic examination to secure thermal equilibrium between the skin and surrounding atmosphere. After equilibration the study takes $\sim 20$ minutes. ${ }^{62}$

Infrared thermography is still not a valid independent diagnostic test for DVT and is not commonly used in clinical practice. The theoretical advantages of thermography are safety, low cost, rapidity of diagnostics, high reproducibility, and no need for trained personnel. Specificity, sensitivity, and accuracy of this test are under investigation and may change with evolution of this technology. A number of studies performed in 1970-1980, mostly prospective cohorts, compared infrared thermography with a gold standard in DVT diagnostics, ascending phlebography (Table 1). Based on the majority of these studies, the thrombosed area was $2.0^{\circ} \mathrm{C}-2.5^{\circ} \mathrm{C}$ warmer compared to the contralateral limb. ${ }^{63}$ Some studies reported lower temperature difference, from $0.4^{\circ} \mathrm{C}$ in thigh to $1.1^{\circ} \mathrm{C}-1.4^{\circ} \mathrm{C}$ in calf areas. ${ }^{48,64} \mathrm{The}$ resolution of infrared thermography was $\sim 0.2^{\circ} \mathrm{C}$ at $30^{\circ} \mathrm{C}$ of ambient temperature. In some cases DVT was associated with decreased temperature of the lower extremity, presumably due to the arterial or microvascular spasm reducing peripheral circu-

Table I The diagnostic potential of infrared thermography compared to ascending phlebography

\begin{tabular}{|c|c|c|c|c|}
\hline Authors & Year & $\begin{array}{l}\text { Number } \\
\text { of legs }\end{array}$ & $\begin{array}{l}\text { Sensitivity } \\
\text { (\%) }\end{array}$ & $\begin{array}{l}\text { Specificity } \\
\text { (\%) }\end{array}$ \\
\hline Cooke and Pilcher ${ }^{79}$ & 1973 & 35 & $6 / 17(94)$ & $17 / 17(100)$ \\
\hline Cooke and Pilcher ${ }^{50}$ & 1974 & 52 & $49 / 52(100)$ & NR \\
\hline Leiviskä and Perttala $^{63}$ & 1975 & 58 & $38 / 4 \mid(93)$ & $6 / 17$ (35) \\
\hline Bergqvist et al ${ }^{68}$ & 1975 & 51 & $27 / 29(93)$ & $20 / 22(91)$ \\
\hline Kalamchi62 & 1976 & 24 & $10 / 14$ (7I) & $8 / 10(80)$ \\
\hline Byström et $\mathrm{al}^{80}$ & 1977 & 51 & $26 / 26(100)$ & $22 / 25(88)$ \\
\hline Bergqvist et $\mathrm{a}^{57}$ & 1977 & 121 & $77 / 87$ (89) & $32 / 34(94)$ \\
\hline Watz et a ${ }^{69}$ & 1979 & 55 & $20 / 21(95)$ & $26 / 34(76)$ \\
\hline Ritchie et $\mathrm{a}^{46}$ & 1979 & 211 & $53 / 72(75)$ & $113 / 139(81)$ \\
\hline Aronen et $\mathrm{a}^{61}$ & 1981 & 140 & $38 / 4 I(93)$ & $80 / 99(81)$ \\
\hline Wallin et $\mathrm{al}^{72}$ & 1983 & 112 & $30 / 39(77)$ & $48 / 73(66)$ \\
\hline Holmgren et $\mathrm{a}^{66}$ & 1990 & 102 & 59/7I (83) & $|7 / 3|(55)$ \\
\hline Lockner et $\mathrm{al}^{81}$ & 1981 & 161 & $95 / 98$ (97) & $31 / 63(49)$ \\
\hline Wojciechowski and & 1981 & 232 & $103 / 111(93)$ & $59 / 122(48)$ \\
\hline \multicolumn{5}{|l|}{ Zachrisson ${ }^{67}$} \\
\hline Pooled data & - & 1405 & $63|/ 79|(80)$ & $479 / 686(70)$ \\
\hline
\end{tabular}

Abbreviation: NR, not reported. lation. ${ }^{63}$ A recent study investigated the diagnostic ability of infrared thermography on experimental rabbit model of femoral vein thrombosis. ${ }^{65}$ Duplex ultrasound and histology were performed to confirm venous thrombosis and its extent. Forty-eight hours after venous thrombosis induction the local temperature was increased for $0.6^{\circ} \mathrm{C}$ compared to the control side $(P<0.05)$, which was clearly distinguished by thermography.

A pooled data estimates the sensitivity and specificity of infrared thermography as $80 \%$ and $70 \%$, respectively (Table 1). The sensitivity of infrared thermography is lower for more distal disease. In one study sensitivity for proximal and distal DVT consisted $88 \%$ and $71 \%$, respectively. ${ }^{66}$ Most false negative results are related to isolated calf or popliteal DVT. ${ }^{67}$ The sensitivity of infrared thermography is lower in patients with nonocclusive and nonpropagating thrombosis. ${ }^{50,63,67,68}$

Infrared thermography is a nonspecific test. Among conditions that may be responsible for the false-positive results are varicose veins, superficial thrombophlebitis, lymphangitis, infection, arthritis, hematoma, muscle tear, ligament sprain, inflamed synovial cyst, ruptured Baker's cyst, and others. ${ }^{67-71}$ Hence, a positive result should be evaluated by duplex ultrasound.

\section{Limitations of the infrared thermography}

While the process of infrared thermography is not operatordependent, the qualitative interpretation of thermograms may be subjective. ${ }^{72}$ The retrospective review of missed DVT cases by infrared thermography indicates that half of them were actually detected, but not interpreted as being positive.$^{67}$ Hence, the method of infrared thermography is interpreter-dependent.

The diagnostic ability of infrared thermography is gradually decreasing with time from the symptoms onset, ${ }^{73}$ and may not be suitable for patients with acute-on-chronic or subacute DVT. ${ }^{63,67}$ Abnormal thermographic pattern remains positive for DVT for at least 3 weeks in most patients, making it a weak follow-up test. ${ }^{67}$ In addition, infrared emission may be chronically increased in patients after a single episode of DVT. Thus, infrared thermography may not be informative for recurrent DVT. In one study $65 \%$ patients with proximal DVT, and 13\% with distal DVT had an abnormal thermography pattern 1 year after initial presentation. ${ }^{74}$ This might be explained by recurrent episodes of venous thrombosis, persistent inflammatory reaction, redistribution of the venous flow to more superficial vessels, or other reasons. ${ }^{74}$

Bilateral thrombosis, due to a higher temperature in both legs, also may not be appreciated by infrared thermography. ${ }^{67}$ 
Interestingly, infrared thermography may also not be sensitive to extensive DVT associated with arterial vasospasm. ${ }^{63} \mathrm{~A}$ strong disadvantage of the infrared thermography is inability to precisely localize thrombotic process. The agreement in localization of venous thrombosis between thermography and phlebography is only $47 \%-79 \% .{ }^{57,69}$ About one-third of patients with extensive DVT reaching the pelvis have an abnormal thermography pattern only in the calf or knee. ${ }^{67}$

\section{Comparison with other diagnostic tests}

Some studies compared infrared thermography with other diagnostic tests. Thus, a prospective study assessed the value of infrared thermography for DVT compared to ${ }^{125} \mathrm{I}$-fibrinogen uptake test in 308 patients. ${ }^{75}$ The sensitivity and specificity of infrared thermography compared to the selected standard was $62 \%$ and $90 \%$, respectively. The sensitivity was lower for distal DVT. The study has several limitations related to the imperfection of the fibrinogen scanning. Another study reported $54 \%$ sensitivity and $49 \%$ specificity of infrared thermography in comparison to fibrinogen scanning. ${ }^{76}$ In a recent noncontrolled nonblinded study involving 64 patients with symptomatic DVT confirmed by compression ultrasonography or angiography, the sensitivity of thermography compared to compression ultrasound was $97 \%$. The agreement between compression ultrasonography and infrared thermography for anatomical distribution of DVT was $83 \%{ }^{48}$ Another technique of measuring the local skin temperature by a special manual infrared scanning transducer (DeVeTherm, Ekoscann AR, Gothenburg, Sweden), that is currently out of market, was proved to be ineffective to detect DVT, with $78 \%-85 \%$ sensitivity and $20 \%-41 \%$ specificity. ${ }^{64,77,78}$

It is worth to mention for historical justice that infrared thermography gained an attention as a possible method in DVT diagnostics in 1970-1980 when ultrasound was not well-appreciated. The main goal was to find a decent screening tool and prevent unnecessary phlebography in many patients. The substantial progress in ultrasound imaging has largely solved the problem. Only a highly sensitive test, such as D-dimer in outpatients with low clinical probability of DVT, may help to improve the current diagnostic strategy.

\section{Conclusion}

The modern evidence-based approach to diagnose DVT with clinical predictive score systems, D-dimer test, and ultrasonography is effective, but not ideal. Many DVT cases remain unverified that increases VTE-related mortality and morbidity. Infrared thermography is a safe, simple, nonexpensive, and noninvasive test that seems to be an attractive modality to initially screen patients suspected for DVT. A highly sensitive test would decrease unnecessary ultrasound exams and increase the detection of those individuals who need to be treated. However, published evidence on the efficacy of the infrared thermography for DVT is inconclusive as being mainly represented by small series performed over the last 30 years. Without the appropriate well-designed modern prospective studies no recommendations for practical use of this method can be done. We conclude that infrared thermography is still an experimental diagnostic test for patients with DVT, and requires more clinical research to support theoretical advantages of the method and suggest its possible clinical application.

\section{Acknowledgment}

The authors want to acknowledge Dr. Robert Schwartz, MD, Chairman of the Board, American Academy of Thermology for providing Figures 2 and 3.

\section{Disclosure}

Jose A. Diaz, MD is a member of the Board of Directors of the American Venous Forum. The authors report no conflicts of interest in this work.

\section{References}

1. Silverstein MD, Heit JA, Mohr DN, Petterson TM, O'Fallon WM, Melton LJ 3rd. Trends in the incidence of deep vein thrombosis and pulmonary embolism: a 25-year population-based study. Arch Intern Med. 1998;158(6):585-593.

2. Tagalakis V, Patenaude V, Kahn SR, Suissa S. Incidence of and mortality from venous thromboembolism in a real-world population: the Q-VTE Study Cohort. Am J Med. 2013;126(9):832.e13-e21.

3. Martinez C, Cohen AT, Bamber L, Rietbrock S. Epidemiology of first and recurrent venous thromboembolism: a population-based cohort study in patients without active cancer. Thromb Haemost. 2014;112(2): 255-263.

4. Alotaibi GS, Wu C, Senthilselvan A, McMurtry MS. Secular trends in incidence and mortality of acute venous thromboembolism: the ABVTE Population-Based Study. Am J Med. 2016;129(8):879.e19-e25.

5. Prandoni P, Lensing AW, Cogo A, et al. The long-term clinical course of acute deep venous thrombosis. Ann Intern Med. 1996;125(1):1-7.

6. Brandjes DP, Buller HR, Heijboer H, et al. Randomised trial of effect of compression stockings in patients with symptomatic proximal-vein thrombosis. Lancet. 1997;349(9054):759-762.

7. Stain M, Schonauer V, Minar E, et al. The post-thrombotic syndrome: risk factors and impact on the course of thrombotic disease. J Thromb Haemost. 2005;3(12):2671-2676.

8. Schulman S, Lindmarker P, Holmstrom M, et al. Post-thrombotic syndrome, recurrence, and death 10 years after the first episode of venous thromboembolism treated with warfarin for 6 weeks or 6 months. J Thromb Haemost. 2006;4(4):734-742.

9. Winsor T, Bendezu J. Thermography and the peripheral circulation. Ann NY Acad Sci. 1964;121:135-156.

10. Lloyd GER, Chadwick J. Hippocratic writings. Harmondsworth: Penguin; 1978.

11. Garagiola U, Giani E. Use of telethermography in the management of sports injuries. Sports Med. 1990;10(4):267-272. 
12. Ishigaki T, Ikeda M, Asai H, Sakuma S. Forehead back thermal ratio for the interpretation of infrared imaging of spinal cord lesions and other neurological disorders. Thermol Int. 1989;3:101-107.

13. Clark S, Dunn G, Moore T, Jayson M 4th, King TA, Herrick AL. Comparison of thermography and laser Doppler imaging in the assessment of Raynaud's phenomenon. Microvasc Res. 2003;66(1):73-76.

14. Ammer K. Diagnosis of raynaud's phenomenon by thermography. Skin Res Tech. 2006;2(4):182-185.

15. Ammer K. The sensitivity of infrared imaging for diagnosing Raynaud's phenomenon or Thoracic Outlet Syndrome is dependent on the method of temperature extraction from thermal images. Thermol Int. 2008; 18(3):81-88.

16. Huang CL, Wu YW, Hwang CL, et al. The application of infrared thermography in evaluation of patients at high risk for lower extremity peripheral arterial disease. J Vasc Surg. 2011;54(4):1074-1080.

17. Ng WK, Ng YK, Tan YK. Qualitative study of sexual functioning in couples with erectile dysfunction: prospective evaluation of the thermography diagnostic system. J Reprod Med. 2009;54(11-12):698-705.

18. Head JF, Elliott RL. Thermography. Its relation to pathologic characteristics, vascularity, proliferation rate, and survival of patients with invasive ductal carcinoma of the breast. Cancer. 1997;79(1):186-188.

19. Arora N, Martins D, Ruggerio D, et al. Effectiveness of a noninvasive digital infrared thermal imaging system in the detection of breast cancer. Am J Surg. 2008;196(4):523-526.

20. Kontos M, Wilson R, Fentiman I. Digital infrared thermal imaging (DITI) of breast lesions: sensitivity and specificity of detection of primary breast cancers. Clin Radiol. 2011;66(6):536-539.

21. Bharara M, Cobb JE, Claremont DJ. Thermography and thermometry in the assessment of diabetic neuropathic foot: a case for furthering the role of thermal techniques. Int J Low Extrem Wounds. 2006;5(4):250-260.

22. Varju G, Pieper CF, Renner JB, Kraus VB. Assessment of hand osteoarthritis: correlation between thermographic and radiographic methods. Rheumatology (Oxford). 2004;43(7):915-919.

23. Niehof SP, Huygen F, van der Weerd RW, Westra M, Zijlstra FJ. Thermography imaging during static and controlled thermoregulation in complex regional pain syndrome type 1. Biomed Eng Online. 2006;5:30.

24. Romano CL, Logoluso N, Dell'Oro F, Elia A, Drago L. Telethermographic findings after uncomplicated and septic total knee replacement. Knee. 2012;19(3):193-197.

25. de Weerd L, Mercer JB, Setså LB. Intraoperative dynamic infrared thermography and free-flap surgery. Ann Plast Surg. 2006;57(3):279-284.

26. Soulen RL, Lapayowker MS, Tyson RR, Korangy AA. Angiography, ultrasound, and thermography in the study of peripheral vascular disease. Radiology. 1972;105(1):115-119.

27. McLachlin J, Richards T, Paterson JC. An evaluation of clinical signs in the diagnosis of venous thrombosis. Arch Surg. 1962;85:738-744.

28. Sandler DA, Martin JF, Duncan JS, et al. Diagnosis of deep-vein thrombosis: comparison of clinical evaluation, ultrasound, plethysmography, and venoscan with X-ray venogram. Lancet. 1984;2(8405):716-719.

29. Bates SM, Jaeschke R, Stevens SM, et al. Diagnosis of DVT: asntithrombotic therapy and prevention of thrombosis, 9th ed: American college of chest physicians evidence-based clinical practice guidelines. Chest. 2012;141(2 Suppl):e351S-e418S.

30. Hull R, Hirsh J, Sackett DL, et al. Clinical validity of a negative venogram in patients with clinically suspected venous thrombosis. Circulation. 1981;64(3):622-625.

31. Goodacre S, Sampson F, Stevenson M, et al. Measurement of the clinical and cost-effectiveness of non-invasive diagnostic testing strategies for deep vein thrombosis. Health Technol Assess. 2006;10(15):1-168, iii-iv.

32. Lin EP, Bhatt S, Rubens D, Dogra VS. The importance of monophasic Doppler waveforms in the common femoral vein: a retrospective study. J Ultrasound Med. 2007;26(7):885-891.

33. Cogo A, Lensing AW, Koopman MM, et al. Compression ultrasound for diagnostic management of patients with clinically suspected deepvein thrombosis: prospective cohort study. BMJ. 1998;316(7124): $17-20$.
34. Wells PS, Hirsh J, Anderson DR, et al. Comparison of the accuracy of impedance plethysmography and compression ultrasonography in outpatients with clinically suspected deep vein thrombosis. A two centre paireddesign prospective trial. Thromb Haemost. 1995;74(6):1423-1427.

35. Wells PS, Lensing AW, Davidson BL, Prins MH, Hirsh J. Accuracy of ultrasound for the diagnosis of deep venous thrombosis in asymptomatic patients after orthopedic surgery. A meta-analysis. Ann Intern Med. 1995; 122(1):47-53.

36. Ouriel K, Green RM, Greenberg RK, Clair DG. The anatomy of deep venous thrombosis of the lower extremity. J Vasc Surg. 2000;31(5):895-900.

37. Lohr JM, Kerr TM, Lutter KS, Cranley RD, Spirtoff K, Cranley JJ. Lower extremity calf thrombosis: to treat or not to treat? J Vasc Surg. 1991; 14(5):618-623.

38. Lohr JM, James KV, Deshmukh RM, Hasselfeld KA. Allastair B. Karmody Award. Calf vein thrombi are not a benign finding. Am J Surg. 1992;170(2):86-90.

39. Kearon C. Natural history of venous thromboembolism. Circulation. 2003;107(23 Suppl 1):I22-004930.

40. Kearon C, Julian JA, Newman TE, Ginsberg JS. Noninvasive diagnosis of deep venous thrombosis. McMaster diagnostic imaging practice guidelines initiative. Ann Intern Med. 1998;128(8):663-677.

41. Winsor T, Winsor D. The noninvasive laboratory-history and future of thermography. Angiology. 1985;36(6):341-353.

42. Astheimer RW, Wormser EM. High speed infrared radiometers. J Opt Soc America. 1959;49(2):179-181.

43. Ring EF. The historical development of thermal imaging in medicine. J Med Eng Technol. 2006;30(4):192-198.

44. Kelly GS. Body temperature variability (Part 1): a review of the history of body temperature and its variability due to site selection, biological rhythms, fitness, and aging. Altern Med Rev. 2006;11(4):278-293.

45. Kelly GS. Body temperature variability (Part 2): masking influences of body temperature variability and a review of body temperature variability in disease. Altern Med Rev. 2007;12(1):49-62.

46. Ritchie WG, Soulen RL, Lapayowker MS. Thermographic diagnosis of deep venous thrombosis. Radiology. 1979;131(2):341-344.

47. Houdas Y, Ring EFJ, editors. Human Body Temperature: Its Measurement and Regulation. New York, NY: Plenum Press; 1982.

48. Deng F, Tang Q, Zeng G, Wu H, Zhang N, Zhong N. Effectiveness of digital infrared thermal imaging in detecting lower extremity deep venous thrombosis. Med Phys. 2015;42(5):2242-2248.

49. Vardasca R. Symmetry of temperature distribution in the upper and lower extremities. Thermol Int. 2008;18(4):154-155.

50. Cooke ED, Pilcher MF. Deep vein thrombosis: preclinical diagnosis by thermography. Br J Surg. 1974;61(12):971-978.

51. Jones BF. A reappraisal of the use of infrared thermal image analysis in medicine. IEEE Trans Med Imaging. 1998;17(6):1019-1027.

52. Nju HH, Lui PW, Hu JS, et al. Thermal symmetry of skin temperature: normative data of normal subjects in Taiwan. Zhonghua Yi Xue Za Zhi (Taipei). 2001;64(8):459-468.

53. Selfe J, Whitaker J, Hardaker N. A narrative literature review identifying the minimum clinically important difference for skin temperature asymmetry at the knee. Thermol Int. 2008;18(2):41-44.

54. Korpelainen JT, Sotaniemi KA, Myllyla VV. Asymmetrical skin temperature in ischemic stroke. Stroke. 1995;26(9):1543-1547.

55. Herry CL, Frize M. Quantitative assessment of pain-related thermal dysfunction through clinical digital infrared thermal imaging. Biomed Eng Online. 2004;3(1):19.

56. Thiruvengadam J, Anburajan M, Menaka M, Venkatraman B. Potential of thermal imaging as a tool for prediction of cardiovascular disease. J Med Phys. 2014;39(2):98-105.

57. Bergqvist D, Efsing O, Hallbook T. Thermography. A noninvasive method for diagnosis of deep venous thrombosis. Arch Surg. 1977;112(5):600-604.

58. Provan JL. Raised skin temperature in the early diagnosis of deep vein thrombosis of the legs. Br Med J. 1965;2(5457):334-337.

59. Hallbook T, Ling L. Resting blood flow at deep venous thrombosis of the leg. Acta Chir Scand. 1972;138(6):581-584. 
60. Madjid M, Naghavi M, Malik BA, Litovsky S, Willerson JT, Casscells W. Thermal detection of vulnerable plaque. Am J Cardiol. 2002;90(10C):36L-39L.

61. Aronen HJ, Suoranta HT, Taavitsainen MJ. Thermography in deep venous thrombosis of the leg. AJR Am J Roentgenol. 1981;137(6):1179-1182.

62. Kalamchi A, Mahoney LJ. Use of the thermography for the early diagnosis of deep vein thrombosis following hip operations. Can J Surg. 1976;19(4):343-347.

63. Leiviskä T, Perttala Y. Thermography in diagnosing deep venous thrombosis of the lower limb. Radiol Clin (Basel). 1975;44(5):417-423.

64. Andersson S. Thermography and plethysmography in the diagnosis of deep venous thrombosis-a comparison with phlebography. Acta Med Scand. 1986;219(4):359-366.

65. Deng F, Tang Q, Zheng Y, Zeng G, Zhong N. Infrared thermal imaging as a novel evaluation method for deep vein thrombosis in lower limbs. Med Phys. 2012;39(12):7224-7231.

66. Holmgren K, Jacobsson H, Johnsson H, Lofsjogard-Nilsson E. Thermography and plethysmography, a non-invasive alternative to venography in the diagnosis of deep vein thrombosis. J Intern Med. 1990; 228(1):29-33.

67. Wojciechowski J, Zachrisson BF. Thermography as a screening method in the diagnosis of deep venous thrombosis of the leg. Acta Radiol Diagn (Stockh). 1981;22(5):581-584.

68. Bergqvist D, Dahlgren S, Efsing O, Hallbook T. Thermographic diagnosis of deep vein thrombosis. Br Med J. 1975;4(5998):684-685.

69. Watz R, Ek I, Bygdeman S. Noninvasive diagnosis of acute deep vein thrombosis. A comparison between thermography, plethysmography and phlebography. Acta Med Scand. 1979;206(6):463-466.

70. Jacobson H. Similar thermographic pattern of deep vein thrombosis and ruptured Baker's cyst. Vasa. 1982;11(2):139-143.

71. Brighton SW, de la Harpie A. Ruptured Baker's cyst mimicking deepvein thrombosis. S Afr Med J. 1984;65(16):649-650.
72. Wallin L, Albrechtsson U, Fagher B, et al. Thermography in the diagnosis of deep venous thrombosis. A comparison with 99Tcm-plasmin test, clinical diagnosis and phlebography. Acta Med Scand. 1983;214(1): $15-20$.

73. Henderson HP, Hackett ME. The value of thermography in peripheral vascular disease. Angiology. 1978;29(1):65-75.

74. Holmgren K, Andersson G, Fagrell B, Johnsson H, Löfsjögård-Nilsson E, Zetterquist $\mathrm{S}$. One-year sequential follow-up of venous emptying rate and leg temperature profiles after acute deep vein thrombosis. Acta Med Scand. 1988;224(6):577-582.

75. Bergqvist D, Hallbook T. Thermography in screening postoperative deep vein thrombosis: a comparison with the 125I-fibrinogen test. Br J Surg. 1978;65(6):443-445.

76. Lindhagen A, Bergqvist D, Hallböök T, Lindroth B. After-exercise thermography and prediction of deep vein thrombosis. Br Med J (Clin Res Ed). 1982;284(6332):1825-1826.

77. Jonker JJ, Sing AK, de Boer AC, den Ottolander GJ. The value of adding thermographic leg scanning to impedance plethysmography in the detection of deep vein thrombosis. Thromb Res. 1986;42(5):681-688.

78. Hamberg O, Madsen G, Hansen PB, et al. Segmental mean temperature differences in the diagnosis of acute venous thrombosis in the legs. Scand J Clin Lab Invest. 1987;47(2):191-193.

79. Cooke ED, Pilcher MF. Thermography in diagnosis of deep venous thrombosis. Br Med J. 1973;2(5865):523-526.

80. Byström LG, Larsson T, Lundell L, Abom PE. The value of thermography and the determination of fibrin-fibrinogen degradation products in the diagnosis of deep venous thrombosis. Acta Med Scand. 1977;202(4): 319-322.

81. Lockner D, Paul C, Hedlund B, Schulman S, Nyman D. Thermography in the diagnosis of DVT. Thromb Haemost. 1981;46(3):652-654.

82. American Academy of Thermology [homepage on the Internet]. Available from: http://aathermology.org/. Accessed December 12, 2016.
Journal of Vascular Diagnostics and Interventions

\section{Publish your work in this journal}

The Journal of Vascular Diagnostics and Interventions is an international, peer-reviewed journal of diagnostics, focusing on non invasive vascular investigation methods involved in the evaluation of vascular diseases. The journal is committed to the rapid publication in the fields of vascular diseases. Original research, review, case reports, expert

\section{Dovepress}

opinion and commentaries are all considered for publication. The manuscript management system is completely online and includes a very quick and fair peer-review system, which is all easy to use. Visit http://www.dovepress.com/testimonials.php to read real quotes from published authors. 